\title{
The safety and effectiveness of MIDLF during one surgeon's initial phase: accuracy, clinical outcome, complications and learning curve
}

Hongtao Ding

Beijing Chaoyang Hospital

Yong Hai ( $\square$ yong.hai@ccmu.edu.cn )

Beijing Chaoyang Hospital https://orcid.org/0000-0002-7206-325X

Yuzeng Liu

Beijing Chaoyang Hospital

Li Guan

Beijing Chaoyang Hospital

Aixing Pan

Beijing Chaoyang Hospital

Bo Han

Beijing Chaoyang Hospital

Research article

Keywords: Learning curve, cortical bone trajectory, midline lumbar fusion, screw displacement, complications

Posted Date: March 9th, 2020

DOI: https://doi.org/10.21203/rs.3.rs-16379/v1

License: (c) (i) This work is licensed under a Creative Commons Attribution 4.0 International License.

Read Full License 


\section{Abstract}

\section{Objective}

To characterize the safety and effectiveness during one surgeon's initial phases of performing a Midline lumbar fusion by freehand technique based on perioperative parameters.

\section{Methods}

The first 90 consecutive patients underwent single level MIDLF, utilized a consistent technique, performed by one surgeon were retrospectively studied. A piecewise regression analysis was performed to evaluate the operation duration based on case number, and to estimate the breakpoint. The early learning period and the late steady phase was divided according to the case number of the breakpoint. Perioperative parameters and clinical data of 2 groups were compared then to elucidate if improvement in operative duration was accompanied by better patient prognosis.

\section{Results}

The inflectional asymptote of the surgeon's learning curve for MIDLF was achieved at the 40th case. The demographics parameters were similar between the early group of 40 patients and the latter 50 . Average surgical time, intraoperative blood loss, length of incision, duration of drainage, postoperative drainage and post-operative hospitalization were significantly less in the late cohort $(p<.05)$. Medial cortical breach was observed in 6/360 cases (4 vs. 2, P>.05), and lateral cortical breach was observed in 35/360 cases (24 vs.11, P<.05). One case of cerebrospinal fluid (CSF) leak, two cases of durotomy and one case of nerve root injury related to the technique was found in the early group, and only one case of durotomy was found in the late group. Post-surgical wound infection was seen in $2.22 \%(\mathrm{~N}=2 / 90)$ of patients (2 vs. $0, P>05)$. The overall complication incidence decreased alone with the learning curve, and statistical difference was achieved. Furthermore, there was no difference in clinical improvement between the two groups.

\section{Conclusions}

Our result indicated that technical proficiency in MIDLF was achieved after 40 surgeries. And it is effective to significantly improve the patients' functional status and relief the pain during one surgeon's learning process of MIDLF in the treatment of lumbar degenerative disease, even in the initial phase. As the surgeon gains surgical proficiency and familiarity with MIDLF procedure, potential complications could be minimized. Furthermore, our results provided evidence to the excellent performance as an alternative option to traditional pedicle screw fixation.

\section{Introduction}

Posterior lumbar fusion is one of the most commonly used surgical methods for the treatment of lumbar degenerative diseases for the advantages of solid construction and high fusion rate of pedicle screw 
internal fixation system[1-3]. However, some drawbacks have been reported as well, including extensive soft tissue and paravertebral muscles exposure, lack of purchase strength in osteoporosis patients and superior facet joint violation[4-6]. The Cortical Bone Trajectory (CBT) technique, first described in 2009 by Santoni et al, was developed as a solution to reduce the incidence of complications associated with conventional pedicle screws[7-11]. While traditional screws engage with cancellous bone, directed convergently along the anatomical axis of the pedicle, CBT screws increase the pullout strength by maximizing thread contact with the cortical bone of the pedicle and vertebrae, which start at the junction of the superior articular process and pars, follows a sagittal caudocephalad path and a medial-lateral path in the transverse plane[7, 10-12].

The superior pullout strength, higher insertional torque and satisfactory stability of the screw-rod construction compared to the traditional fixation have been confirmed by biomechanical studies[7, 10, 1218]. And the comparable clinical outcomes, less multifidus muscle damage and less complications associated with instrumentations compared to PS have been observed in clinical studies[19-24]. However, the CBT screws placement accuracy, surgical parameters and complications in one surgeon's learning curve could rarely be found in literature. The misplacement screws may lead to severe complications including nerve root injury, cerebrospinal fluid (CSF) leak, and even spinal cord injury. It is reported the incidence of misplacement with CBT was $4 \%-12.5 \%[25,26]$. According to Zachary et al, the unsafe cortical screws appeared in $22 \%$ cases by free-hand insertion[27]. Although it was demonstrated a safe procedure of cortical bone trajectory screw insertion under the guidance of intra-operative fluoroscopic and CT in one surgeon's learning curve[22], what if we don't have the intro-operative guidance? With the utilization of this emerging technique, patients may experience an increased incidence of complications in one surgeon's training process. We aim to characterize the safety and effectiveness by describing the accuracy, surgical parameters, clinical outcome and surgical complications of midline lumbar fusion (MIDLF) in one surgeon's learning curve without any intra-operative guidance.

\section{Material And Methods}

\subsection{General data}

We applied the institutional approval first. Retrospective data were collected from the senior surgeon's first 90 patients undergoing a single level midline lumbar fusion from 2017 to 2018, patients of revision cases and multilevel procedures have been excluded. Informed patient consent was obtained at the time of treatment for all patients in the study. A total of 360 cortical screws were placed. Every patient had a diagnosis of either degenerative disk disease or spinal stenosis. With at least 12 months follow up, the clinical/ radiologic recovery data and complications of all patients were collected and analyzed.

\subsection{Surgical technique}

After anesthesia, a small incision was made at the fusion segment, the paraspinal muscles and soft tissue were given blunt separation limited in the inferior facet joint process sagittally and lateral border of isthmus coronally, respecting the integrity of the muscle and providing a bilateral window to the lamina 
and articular process. After exposure, the insertion point was located at the intersection of 2-3mm beneath the inferior border of the inferior facet of cephalad segment and 2-3mm medial to the lateral border of isthmus, the cortex of the entry point was drilled, pedicle finder was used to prepare the trajectory angled approximately $20^{\circ}$ from medial to lateral, $30^{\circ}$ to $45^{\circ}$ from inferior to superior, and the initial $1 / 3$ to $1 / 2$ (about $2-3 \mathrm{~cm}$ ) trajectory of the screw holes were line-to-line tapped with screw taps. Then a pedicle probe was inserted to testify the integrality of screw trajectory wall, and mark screws were placed tentatively. C-arm X-ray images were carried out to view the screws' position. After preparing the trajectory, the decompression including laminotomy and partial or total facetectomy was performed according to pathological conditions. After intervertebral disc tissue was completely and carefully removed, one PEEK cage filled with local bone graft were inserted into the intervertebral space, and local bone blocks were inserted lateral to the cages. Then, right-sized cortical screws and rods (CD HORIZON ${ }^{\circledR}$ SOLERA $^{\text {TM }} 4.75$ Spinal System, Medtronic, USA) were placed. Lastly, one drainage tube was placed beneath the paraspinal muscles (Fig. 1 and Fig. 2). All cortical screws were inserted by one spine surgeon without an intraoperative navigation system.

\subsection{Methods}

The consecutive patient was recorded according to the operation data, and a piecewise regression analysis was performed in R statistical software (version 3.6.1) to evaluate the operation duration based on case number (Fig. 3). Using the mathematical algorithm described by Muggeo[28] to estimate the breakpoint and its $95 \%$ confidence limit, assuming that a best-fit line in the scatter plot comprised by 2 (or more) straight lines connected at the breakpoint. The early learning period and the late steady phase was divided according to the case number of the breakpoint. Perioperative parameters and clinical data of 2 groups would then be compared to elucidate if improvement in operative duration was accompanied by better patient prognosis.

\subsection{Outcome measures}

The early experience group were compared with the late experience group based on intro-operative and post-operative outcomes measures, including duration of surgery (skin to skin), intraoperative blood loss, length of incision, postoperative drainage, duration of drainage and post-operative duration of hospitalization. The perioperative complications we examined in this study were nerve root injury due to hardware misplacement, CSF leak caused by dural tear. The screws specification was recorded. In addition, the accuracy of CBT screws placement was assessed on postoperative CT using Kasim's classification and grading system[29]. During the follow-up, the presence of hardware malfunction breakage or pullout of cortical screws and pseudarthrosis (the cage subsidence and graft migration) were recorded as complications. The fusion status was accessed by CT after 12 months post-operation utilizing the criteria introduced by Sreeharsha[30]. The contiguous 2.0-mm axial-cut images perpendicular to the disc space were obtained at the operative level. As well as the sagittal and coronal reconstructions. Clinical outcome was evaluated by visual analogue scores (VAS) for back and leg pain and Oswestry Disability Index (ODI). 


\subsection{Statistical analysis}

The SPSS version 18 software (IBM Corp., Armonk, NY) was used to perform statistical analysis. 2samples independent $T$ test was conducted to assess for differences of continuous variables with parametric data between the 2 cohorts. ' $c$ and Fisher's exact test were used to analyze differences of categorical variables in outcome variables, where a $\mathrm{p}$ value of 0.05 or less denoting statistical significance.

\section{Result}

90 consecutive patients were included, underwent decompression and lumbar instrumented with cortical screws. Based on the piecewise regression analysis, the surgeon's operative time for performing singlelevel MIDLF was estimated to stabilize after performing the $40^{\text {th }}$ operation $(95 \% \mathrm{Cl}, 38-42)$. Taking the $40^{\text {th }}$ case as the reference point, the early experience group would include 40 patients and the late group consist 50 patients. There was no significant difference comparing the early group of 40 patients to the late 50 in patient demographics, namely age, sex, operated level, and body mass index (Table 1).

\subsection{Perioperative parameters}

Almost all perioperative parameters improved significantly during the learning curve. The average surgery time decreased from 179.58 mins to 120.92 mins, the estimated intraoperative blood loss was $209.63 \mathrm{ml}$ in the early group, shrinking to $111.10 \mathrm{ml}$ in late one. The length of incision was shortened from 69.73 $\mathrm{mm}$ to $57.22 \mathrm{~mm}$. And the duration of drainage and postoperative hospitalization were reduced from 3.15 days and 5.18 days to 2.12 days and 4.10 days, respectively. As for the postoperative drainage, reducing from $190 \mathrm{ml}$ to $145 \mathrm{ml}$. All improvement above were statistically significant (Details in Table 1). The screws specification was shown in Fig. 4.

\subsection{Clinical outcomes}

Two groups exhibited similar preoperative baseline pain and disability parameters, and all 90 patients got clinical improvement postoperative. For VAS, the early group rated a mean score of $6.85 \pm 1.00$ preoperatively, decreasing to $0.63 \pm 0.66$ at final follow-up, the late group from $6.90 \pm 0.81$ to $0.60 \pm 0.49$, without statistical significance. Regarding ODI, the early group was $78.13 \pm 7.59$ before operation, improving to $5.00 \pm 1.88$ one year after operation, the late group from $79.94 \pm 5.00$ to $5.88 \pm 3.78$. The VAS and ODI score in both groups got significant improvement comparing with the status pro-operative, however, no statistical difference was shown between the 2 groups (Table 2).

\subsection{Radiologic outcome}

According to the criteria introduced by Sreeharsha, the fusion rate of $90.00 \%(36 / 40)$ in the early group, $88.00 \%(44 / 50)$ in the late group, no statistical significance in fusion rate at final follow-up between two groups. 


\subsection{Accuracy of cortical screws placement}

360 screws were placed, 160 screws in the early group, 200 in the late group. We found four types misplacement of screws in this study: medial and lateral cortical bone tresis, endplate tresis and foraminal tresis (Table 3). Medial pedicle breach was observed in $6 / 360$ screws on post-operative CT scan, with an incidence of $1.67 \%$. Lateral pedicle breach was observed in $35 / 360$ screws, for an incidence of $9.72 \%$. Foraminal tresis was observed in $3 / 360$ screws, with an incidence of $0.83 \% .66 .67 \%(4 / 6)$ medial pedicle breach and $68.57 \%(24 / 35)$ lateral pedicle breach occurred in the early experience phase of the study. All cases of foraminal tresis $(\mathrm{N}=3)$ were also identified in this phase (Fig. 5).

\subsection{Complications}

Complications are grouped into intro-operatively and post-operatively from the surgery date to the last follow-up. Durotomy was seen in three patients of the cohort (3/90,3.33\%). In two patients of them, durotomy occurred in the process of releasing adhesions from the severe central ligament hypertrophy and decompression. Durotomy was identified and repaired primarily at the time of decompression was completed. In the third case, the cortical screw broke the medial cortex of right pedicle, pierced the dura mater of the nerve root, and squeezed the L5 transition nerve root, leading to a CSF leak, neurologic radicular symptoms and nerve root deficit. It is noted that two patients among them was record in the early experience group, and the misplaced screw was included. Post-operative wound infection was seen in two patients in early experience group, and debridement was needed in neither of them. For radiologic outcomes, one patient of pseudarthrosis was seen in early experience group. The late experience group exhibited a higher proportion of solid fusion. However, no significant difference was demonstrated at the final follow-up. There was no case of hardware malfunction in the cohort.

However, no significant difference was shown in CSF leak, durotomy and nerve root injury between the early and late groups. The details are shown in Table 3.

The screw misplacement-related complications were recorded. There was one nerve root deficit and one durotomy caused by the medial breach screws in 6 medially placed screws while none event in 35 laterally inserted screws. The complications incidence cause by medial breach screws is statistically higher than by lateral breach screws $(p=0.018)$.

\section{Discussion}

Midline lumbar fusion, providing comparable biomechanical purchase and clinical outcomes, is a relatively emerging technique and an efficient alternative option in the treatment of lumbar degenerative disease. However, whether it is a surgically challenging and familiarity demanding operation? What about the safety and effectiveness during the learning process? There are few literatures available detailing the process in which a spinal surgeon becomes competent with MIDLF. The outcomes, accuracy and complications during the learning curve remain vague. 
Attempting to characterize the safety and effectiveness during one surgeon's initial learning phase with MIDLF procedures by freehand technique, a formal statistical method (piecewise regression analysis) was utilized to determine the breakpoint in the learning curve, which occurred at the $40^{\text {th }}$ case. To reduce the confounding factors in the study, one senior spine surgeon performed all the single-level MIDLF cases in this single center study. And independent assessors excluding the surgeon performed the data collection and analysis to further reduce biasness.

\section{More familiar with surgical procedures: a natural process}

In our study, the intraoperative outcomes improved with the increasing case numbers. Significant changes were identified between the two groups in average surgical time, intraoperative blood loss and length of incision. The results were consistent with that in similar cohorts[31]. The average surgical time ranged from $117.8 \mathrm{~min}$ to $237.6 \mathrm{~min}[8,20]$, and $119 \mathrm{ml}$ to $276.5 \mathrm{ml}[21,32]$ for intraoperative blood loss in previous studies of single level cortical screw fixation surgery[21,32-34]. The reduction of duration of surgery should be attributed to technical competence achievement. Surgeon's familiarity of anatomy and key surgical procedures played an important role in the improvement. Additionally, the tacit cooperation of surgery team made dedicated efforts to raise surgical efficiency by familiarizing surgery steps and modifying the workflow.

\section{Purposeful attention to soft tissue handling yields visible benefits}

The late experience cohort had significantly less intraoperative blood loss, about $47 \%$ less than the early group. The advantage was due to two reasons: firstly, on account of a shorter operative time, patients in the late group were exposed in a shorter duration. Moreover, as the surgeon gains familiarity with surgical technique and anatomy, the improvement in soft tissue management and paraspinal muscles dissection resulted in less tissue damage, translating to less blood loss. Furthermore, thanks to this familiarity and improvement of surgery technique, a significantly shorter invasion was required in patients of the late group.

As the indicators of postoperative recovery, the less postoperative drainage, duration of drainage and postoperative hospitalization means the better and faster recovery. It should be noted that the drain tube is usually removed after it is less than $50 \mathrm{ml}$ every 24 hours in our institution. Although there was no significant difference in postoperative drainage between the 2 groups, duration of drainage and postoperative hospitalization in the late group was significantly less than the early. The surgeon's purposeful attention to soft tissue handling, protection of muscles and hemostasis led to less trauma and damage, which could yield visible short-term interest and potential further benefits to the patients[8].

\section{The valid procedure of MIDLF could be mastered early: the decompression and insertion accuracy}

Although the function and pain of patients in both cohorts got huge improvement comparing with preoperative status according to VAS and ODI, however, no significant difference was demonstrated in either the preliminary outcomes or the mid-term during the follow-up. This lack of significant differences 
between the 2 groups illustrated that the valid decompression procedure of MIDLF could be efficiently mastered relatively early.

CBT screws rely on four-point purchase between the dorsal cortex at the site of insertion, the medial and lateral cortex of pedicle wall and the curvature of the vertebral body wall, to maximize the cortical bone contact to improve purchase strength[18], but inaccurate placement may give rise to suboptimal fixation even nerve injury. We took five types misplacement into account in the study. There were $6(6 / 360,1.67 \%)$ screws penetrating medial cortex of pedicle, 35 (35/360, 9.72\%) screws penetrating lateral cortex, 2 $(2 / 360,0.56 \%)$ endplate tresis and $3(3 / 360,0.83 \%)$ foraminal tresis respectively. A totally breach incidence of $12.78 \%$ was presented, which was a little bit higher than Wray's $11.4 \%$, Kasukawa's $9.5 \%$ and Dayani's 7\%[35-37].

The authors assume that the difference could be partly explained by the freehand screws insertion and the diverse evaluation system and method used in different studies. All screws in this study were placed without any intraoperative navigation system, however, in Kasukawa's and Dayani's research, all patients underwent cortical screw placement using fluoroscopic guidance or intra-operative CT guidance. Comparing with taking intraoperative guidance as reference, our surgeon located the entry point and inserted screws carefully by scrutinizing spine landmarks only, yet osteoproliferation, synostosis and other malformations were more likely came into being in these landmark structures in patients with lumbar degenerative disease. Therefore, screws misplacement rate tended towards higher since the surgeon was misguided. Additionally, one comprehensive and detailed evaluation method based on CT scan images including five kinds of misplaced insertion was utilized to assess the placement accuracy, we believe that the absence of intraoperative navigation system and the utilization of precise evaluation system could make contribution to the higher breach incidence somehow.

A brief comparison for misplacement rate was conducted between the early and late groups. Significant difference was identified in lateral pedicle breach $(24 \mathrm{vs.} 11, \mathrm{p}=0.003)$ and total misplacement $(30 \mathrm{vs} .13$, $\mathrm{p}=0.000$ ). The late phase group had $54.17 \%$ less lateral pedicle breach rate and $56.67 \%$ less total misplacement rate than the early phase. The significant improvement suggested that there was an explicit learning curve associated with the placement accuracy. In the initial phase of the cohort, the surgeon was not familiar with the medial-to-lateral trajectory for the relatively emerging technique. According to the anatomical characteristic of fleeing away from nerve root, the surgeon assumed that it is much safer to cannulate the screw more laterally, which could explain the incidence of lateral pedicle breach was quite higher than the medial kind, even in the late phase. Over time and with increasing experience, even freehand insertion technique could be modified and proficiently executed to prevent pedicle from being penetrated.

\section{Practice makes perfect: the complications}

Although MIDLF is less invasive and offers comparable outcomes to traditional fixation, complications exist. The occurrence of perioperative complications in the early group did not differ significantly from that in the late groups respectively. These perioperative complications highlight the intrinsic peculiar 
property of lumbar decompression and fusion procedure, even as technical competency is achieved and efficiency is improved. The incidence of intraoperative complications presented in our study was consistent with the finding of Sakaura's[19] and Patel's[38]. During at least 12 months' follow-up, none hardware malfunction, one case of pseudarthrosis (in the early group) and similar fusion rate were found in all patients, as evaluated by flexion-extension X-rays and CT. The result was consistent with Ninomiya's study, indicating that rare radiology evidence of hardware complications[39], which is the intrinsic advantage of CBT in osteoporosis patients[7]. The coherence of complications incidence in different studies demonstrated the safety in one's initial phase experience of MIDLF procedures.

After the overall complications were summarized, the significant lower incidence of overall complications $(17.50 \%$ vs. $2.00 \%, p=0.028)$ was shown in the late cohort. The result demonstrated that as the surgeon gains familiarity with the procedure these potential complications can be minimized to some extent.

There was a significant higher incidence of complication due to medially placed screws than caused by laterally inserted $(33.33 \%$ vs. $0.0 \%, p=0.018)$. The result was consistent to a certain degree to the assumption we introduced before, that it is much safer to cannulate the screw more laterally. The laterally placed screws may negatively affect the biomechanical properties and purchase strength of cortical fixation, yet we have no evidence and reference. Therefore, we recommend the practicing surgeons to select a lateral relatively trajectory if they cannot ensure the accurate screws insertion.

We recognize that our study has its limitations. Firstly, the results are based on the experience of only one single spine surgeon in one institution, the results may not be broadly applicable, future studies should be conducted to portray a surgical learning curve of multiple surgeons. Secondly, with a small sample size, the study is underpowered to elucidate meaningful interpretations in all variables. Thirdly, the surgeon also performed other lumbar surgeries during the study period, these additional procedures could possibly improve his MIDLF operative proficiency. And lastly, retrospective study carries inherent bias in nature, even though we attempt to avoid this bias.

\section{Conclusion}

Our result indicated that technical proficiency in MIDLF was achieved after 40 surgeries. And it is safe and effective to significantly improve the patients' functional status and relief the pain during one surgeon's learning process of MIDLF by free-hand technique in the treatment of lumbar degenerative disease, even in the initial phase. Surgical techniques and proficiency improved with achievement of surgical competency and understanding the method. Moreover, our result indicated that as the surgeon gains familiarity with the MIDLF procedure these potential complications can be minimized. Furthermore, our results provided evidence to the explicit safety of CBT screws freehand insertion and the excellent performance as an alternative option to traditional pedicle screw fixation.

\section{Abbreviations}


$\mathrm{CBT}$, cortical bone trajectory

$\mathrm{CT}$, computed tomography

MIDLF, midline lumbar fusion

CSF: cerebrospinal fluid

VAS, visual analogue scores

ODI, Oswestry Disability Index

\section{Declarations}

Ethics approval and consent to participate

The study was in accordance with the ethical standards of the institutional research committee, the 1964 Helsinki declaration, and its later amendments.

Consent for publication

All authors read and approved the final manuscript for publication.

Competing interests

The authors declare that they have no competing interests

Funding

None

Authors' contributions

Hongtao Ding, Yuzeng Liu and Li Guan as the observer reviewed the screws position.

Aixing Pan and Bo Han analyzed and interpreted the patient data. Hongtao Ding and

Yong Hai were major contributors in writing the manuscript. All authors read and approved the final manuscript.

Acknowledgements

Not applicable

\section{References}


1. Lee N, Kim KN, Yi S, Ha Y, Shin DA, Yoon DH, Kim KS (2017) Comparison of Outcomes of Anterior, Posterior, and Transforaminal Lumbar Interbody Fusion Surgery at a Single Lumbar Level with Degenerative Spinal Disease. World Neurosurg 101:216-226. doi: 10.1016/j.wneu.2017.01.114

2. Lidar Z, Beaumont A, Lifshutz J, Maiman DJ (2005) Clinical and radiological relationship between posterior lumbar interbody fusion and posterolateral lumbar fusion. Surg Neurol 64:303-308; discussion 308. doi: 10.1016/j.surneu.2005.03.025

3. Cheng X, Zhang K, Sun X, Zhao C, Li H, Ni B, Zhao J (2017) Clinical and radiographic outcomes of bilateral decompression via a unilateral approach with transforaminal lumbar interbody fusion for degenerative lumbar spondylolisthesis with stenosis. The spine journal : official journal of the North American Spine Society 17:1127-1133. doi: 10.1016/j.spinee.2017.04.011

4. Babu R, Park JG, Mehta Al, Shan T, Grossi PM, Brown CR, Richardson WJ, Isaacs RE, Bagley CA, Kuchibhatla M, Gottfried ON (2012) Comparison of superior-level facet joint violations during open and percutaneous pedicle screw placement. Neurosurgery 71:962-970. doi: 10.1227/NEU.0b013e31826a88c8

5. Liu J, Deng H, Long X, Chen X, Xu R, Liu Z (2016) A comparative study of perioperative complications between transforaminal versus posterior lumbar interbody fusion in degenerative lumbar spondylolisthesis. Eur Spine J 25:1575-1580. doi: 10.1007/s00586-015-4086-8

6. Mehta VA, McGirt MJ, Garces Ambrossi GL, Parker SL, Sciubba DM, Bydon A, Wolinsky JP, Gokaslan ZL, Witham TF (2011) Trans-foraminal versus posterior lumbar interbody fusion: comparison of surgical morbidity. Neurol Res 33:38-42. doi: 10.1179/016164110X12681290831289

7. Santoni BG, Hynes RA, McGilvray KC, Rodriguez-Canessa G, Lyons AS, Henson MA, Womack WJ, Puttlitz CM (2009) Cortical bone trajectory for lumbar pedicle screws. The spine journal : official journal of the North American Spine Society 9:366-373

8. Hung CW, Wu MF, Hong RT, Weng MJ, Yu GF, Kao CH (2016) Comparison of multifidus muscle atrophy after posterior lumbar interbody fusion with conventional and cortical bone trajectory. Clin Neurol Neurosurg 145:41-45. doi: 10.1016/j.clineuro.2016.03.005

9. Cawley DT, Alexander M, Morris S (2014) Multifidus innervation and muscle assessment post-spinal surgery. Eur Spine J 23:320-327. doi: 10.1007/s00586-013-2962-7

10. Matsukawa K, Yato Y, Nemoto O, Imabayashi H, Asazuma T, Nemoto K (2013) Morphometric measurement of cortical bone trajectory for lumbar pedicle screw insertion using computed tomography. J Spinal Disord Tech 26:E248-253

11. Matsukawa K, Kato T, Yato Y, Sasao H, Imabayashi H, Hosogane N, Asazuma T, Chiba K (2016) Incidence and Risk Factors of Adjacent Cranial Facet Joint Violation Following Pedicle Screw Insertion Using Cortical Bone Trajectory Technique. Spine (Phila Pa 1976) 41:E851-856. doi: 10.1097/BRS.0000000000001459

12. Matsukawa K, Taguchi E, Yato Y, Imabayashi H, Hosogane N, Asazuma T, Nemoto K (2015) Evaluation of the Fixation Strength of Pedicle Screws Using Cortical Bone Trajectory: What Is the Ideal Trajectory for Optimal Fixation? Spine (Phila Pa 1976) 40:E873-878 
13. Matsukawa K, Yato Y, Hynes RA, Imabayashi H, Hosogane N, Asazuma T, Matsui T, Kobayashi Y, Nemoto K (2017) Cortical Bone Trajectory for Thoracic Pedicle Screws: A Technical Note. Clin Spine Surg 30:E497-E504

14. Matsukawa K, Yato Y, Imabayashi H, Hosogane N, Abe Y, Asazuma T, Chiba K (2016) Biomechanical evaluation of fixation strength among different sizes of pedicle screws using the cortical bone trajectory: what is the ideal screw size for optimal fixation? Acta Neurochir (Wien) 158:465-471

15. Matsukawa K, Yato Y, Imabayashi H, Hosogane N, Asazuma T, Chiba K (2016) Biomechanical evaluation of lumbar pedicle screws in spondylolytic vertebrae: comparison of fixation strength between the traditional trajectory and a cortical bone trajectory. J Neurosurg Spine 24:910-915. doi: 10.3171/2015.11.SPINE15926

16. Matsukawa K, Yato Y, Imabayashi H, Hosogane N, Asazuma T, Nemoto K (2015) Biomechanical evaluation of the fixation strength of lumbar pedicle screws using cortical bone trajectory: a finite element study. J Neurosurg Spine 23:471-478

17. Matsukawa K, Yato Y, Imabayashi H, Hosogane N, Asazuma T, Nemoto K (2015) Biomechanical Evaluation of Cross Trajectory Technique for Pedicle Screw Insertion: Combined Use of Traditional Trajectory and Cortical Bone Trajectory. Orthop Surg 7:317-323

18. Matsukawa K, Yato Y, Kato T, Imabayashi H, Asazuma T, Nemoto K (2014) In vivo analysis of insertional torque during pedicle screwing using cortical bone trajectory technique. Spine (Phila Pa 1976) 39:E240-245

19. Sakaura H, Miwa T, Yamashita T, Kuroda Y, Ohwada T (2016) Posterior lumbar interbody fusion with cortical bone trajectory screw fixation versus posterior lumbar interbody fusion using traditional pedicle screw fixation for degenerative lumbar spondylolisthesis: a comparative study. J Neurosurg Spine 25:591-595

20. Sakaura H, Miwa T, Yamashita T, Kuroda Y, Ohwada T (2018) Cortical bone trajectory screw fixation versus traditional pedicle screw fixation for 2-level posterior lumbar interbody fusion: comparison of surgical outcomes for 2-level degenerative lumbar spondylolisthesis. J Neurosurg Spine 28:57-62

21. Takenaka S, Mukai Y, Tateishi K, Hosono N, Fuji T, Kaito T (2017) Clinical Outcomes After Posterior Lumbar Interbody Fusion: Comparison of Cortical Bone Trajectory and Conventional Pedicle Screw Insertion. Clin Spine Surg 30:E1411-E1418

22. Dayani F, Chen YR, Johnson E, Deb S, Wu Y, Pham L, Singh H (2018) Minimally invasive lumbar pedicle screw fixation using cortical bone trajectory - Screw accuracy, complications, and learning curve in 100 screw placements. J Clin Neurosci

23. Dabbous B, Brown D, Tsitlakidis A, Arzoglou V (2016) Clinical outcomes during the learning curve of MIDline Lumbar Fusion (MIDLF ${ }^{\circledR}$ ) using the cortical bone trajectory. Acta Neurochirurgica 158:14131420

24. Liu YZ, Hai Y, Zhang XN, Yin P, Liu T, Ding HT, Han CF, Han B, Tao LM, Guan L (2019) [Comparison of cortical bone trajectory screw fixation and pedicle screw fixation in posterior lumbar fusion]. Zhonghua Yi Xue Za Zhi 99:1473-1478. doi: 10.3760/cma.j.issn.0376-2491.2019.19.008 
25. Ohkawa T, Iwatsuki K, Ohnishi Y, Ninomiya K, Yoshimine T (2015) Isthmus-guided Cortical Bone Trajectory Reduces Postoperative Increases in Serum Creatinine Phosphokinase Concentrations. Orthop Surg 7:232-238. doi: 10.1111/os.12189

26. Iwatsuki K, Yoshimine T, Ohnishi Y, Ninomiya K, Ohkawa T (2014) Isthmus-guided cortical bone trajectory for pedicle screw insertion. Orthop Surg 6:244-248. doi: 10.1111/os.12122

27. Tan Z, McLachlin S, Whyne C, Finkelstein J (2019) Validation of a freehand technique for cortical bone trajectory screws in the lumbar spine. J Neurosurg Spine:1-8. doi:

10.3171/2019.1.SPINE181402

28. Muggeo VM (2003) Estimating regression models with unknown break-points. Stat Med 22:30553071. doi: 10.1002/sim. 1545

29. Abul-Kasim K, Strombeck A, Ohlin A, Maly P, Sundgren PC (2009) Reliability of low-radiation dose CT in the assessment of screw placement after posterior scoliosis surgery, evaluated with a new grading system. Spine (Phila Pa 1976) 34:941-948

30. Nandyala SV, Fineberg SJ, Pelton M, Singh K (2014) Minimally invasive transforaminal lumbar interbody fusion: one surgeon's learning curve. The spine journal : official journal of the North American Spine Society 14:1460-1465. doi: 10.1016/j.spinee.2013.08.045

31. Zhang T, Guo N, Chen T, Yan J, Zhao W, Xu G (2019) Comparison of outcomes between cortical screws and traditional pedicle screws for lumbar interbody fusion: a systematic review and metaanalysis. J Orthop Surg Res 14:269. doi: 10.1186/s13018-019-1311-x

32. Marengo N, Ajello M, Pecoraro MF, Pilloni G, Vercelli G, Cofano F, Zenga F, Ducati A, Garbossa D (2018) Cortical Bone Trajectory Screws in Posterior Lumbar Interbody Fusion: Minimally Invasive Surgery for Maximal Muscle Sparing-A Prospective Comparative Study with the Traditional Open Technique. Biomed Res Int 2018:7424568. doi: 10.1155/2018/7424568

33. Peng J, Zhan Y, Liu Y, Zong Y, Mao Y (2017) [Comparison of effectiveness of cortical bone trajectory screw fixation and pedicle screw fixation in posterior lumbar interbody fusion]. Zhongguo Xiu Fu Chong Jian Wai Ke Za Zhi 31:1341-1345. doi: 10.7507/1002-1892.201706075

34. Hoffman H, Verhave B, Jalal MS, Beutler T, Galgano MA, Chin LS (2019) Comparison of Cortical Bone Trajectory Screw Placement Using the Midline Lumbar Fusion Technique to Traditional Pedicle Screws: A Case-Control Study. Int J Spine Surg 13:33-38. doi: 10.14444/6005

35. Dayani F, Chen YR, Johnson E, Deb S, Wu Y, Pham L, Singh H (2019) Minimally invasive lumbar pedicle screw fixation using cortical bone trajectory - Screw accuracy, complications, and learning curve in 100 screw placements. J Clin Neurosci 61:106-111. doi: 10.1016/j.jocn.2018.10.131

36. Wray S, Mimran R, Vadapalli S, Shetye SS, McGilvray KC, Puttlitz CM (2015) Pedicle screw placement in the lumbar spine: effect of trajectory and screw design on acute biomechanical purchase. $J$ Neurosurg Spine 22:503-510

37. Kasukawa Y, Miyakoshi N, Hongo M, Ishikawa Y, Kudo D, Shimada Y (2015) Short-Term Results of Transforaminal Lumbar Interbody Fusion Using Pedicle Screw with Cortical Bone Trajectory Compared with Conventional Trajectory. Asian Spine J 9:440-448. doi: 10.4184/asj.2015.9.3.440 
38. Patel SS, Cheng WK, Danisa OA (2016) Early complications after instrumentation of the lumbar spine using cortical bone trajectory technique. J Clin Neurosci 24:63-67

39. Ninomiya K, Iwatsuki K, Ohnishi Y, Ohkawa T, Yoshimine T (2015) Clear Zone Formation around Screws in the Early Postoperative Stages after Posterior Lumbar Fusion Using the Cortical Bone Trajectory Technique. Asian Spine J 9:884-888

\section{Tables}

Table 1 Patient demographics and perioperative parameters

\begin{tabular}{cccc}
\hline & $\begin{array}{c}\text { Early experience } \\
\text { group } \\
(\mathrm{N}=40)\end{array}$ & $\begin{array}{c}\text { Late experience } \\
\text { group } \\
(\mathrm{N}=50)\end{array}$ & P value \\
\hline Demographics Parameters & $63.25 \pm 7.68$ & $65.24 \pm 9.47$ & 0.285 \\
Age (yrs.) & $19: 21$ & $23: 27$ & 1.000 \\
Gender (male: female) & $26.88 \pm 3.66$ & $26.29 \pm 2.80$ & 0.407 \\
BMI $\left(\mathrm{kg} / \mathrm{m}^{2}\right)$ & $0: 3: 33: 4$ & $1: 4: 39: 6$ & 0.958 \\
Surgical level $\left(\mathrm{L}_{2 / 3}: \mathrm{L}_{3 / 4}: \mathrm{L}_{4 / 5}: \mathrm{L}_{5} / \mathrm{S}_{1}\right)$ & & & \\
Perioperative Parameters & $179.58 \pm 37.95$ & $120.92 \pm 12.71$ & $0.000 \dagger$ \\
Average surgical time (min) & $209.63 \pm 72.04$ & $111.10 \pm 21.39$ & $0.000 \dagger$ \\
Intraoperative blood loss $(\mathrm{ml})$ & $69.73 \pm 6.03$ & $57.22 \pm 6.29$ & $0.000 \dagger$ \\
Length of incision (mm) & $189.93 \pm 80.08$ & $145.46 \pm 59.29$ & $0.005 \dagger$ \\
Postoperative drainage $(\mathrm{ml})$ & $3.15 \pm 1.03$ & $2.12 \pm 0.52$ & $0.000 \dagger$ \\
Duration of drainage (days) & $5.18 \pm 1.45$ & $4.10 \pm 0.97$ & $0.000 \dagger$ \\
Postoperative hospitalization & & & \\
(days) & & &
\end{tabular}

BMI, Body Mass Index;

Values are expressed as the mean \pm standard deviation, unless indicated otherwise

$\dagger P<0.05$, statistically significant.

Table 2 Clinical Outcome Parameters 


\begin{tabular}{cccc}
\hline Clinical Outcome Parameters & Early experience group & Late experience group & P value $^{*}$ \\
\hline Pain (VAS) & $6.85 \pm 1.00$ & $6.90 \pm 0.81$ & 0.794 \\
Pre-operation & $3.10 \pm 0.71$ & $2.94 \pm 0.68$ & 0.280 \\
3 mo. & $1.33 \pm 0.69$ & $1.42 \pm 0.73$ & 0.533 \\
6 mo. & $0.63 \pm 0.66$ & $0.60 \pm 0.49$ & 0.838 \\
1 yr. & 0.000 & 0.000 & $/$ \\
P value & & & \\
Oswestry Disability Index (ODI) & $78.13 \pm 7.59$ & $79.94 \pm 5.00$ & 0.560 \\
Pre-operation & $33.43 \pm 6.44$ & $35.52 \pm 6.23$ & 0.122 \\
3 mo. & $15.60 \pm 3.59$ & $17.22 \pm 6.68$ & 0.145 \\
6 mo. & $5.00 \pm 1.88$ & $5.88 \pm 3.78$ & 0.155 \\
1 yr. & 0.000 & 0.000 & $/$ \\
P value & & &
\end{tabular}

VAS, Visual Analogue Scale.

ODI, Oswestry Disability Index.

Values are expressed as the mean \pm standard deviation, unless indicated otherwise

* The comparison between early and late groups.

\# The results comparison between pre-operation and 1 year after operation.

Table 3 The accuracy of cortical screws placement and complications

\begin{tabular}{cccc}
\hline Parameters & $\begin{array}{c}\text { Early experience group } \\
\text { (160 screws) }\end{array}$ & $\begin{array}{c}\text { Late experience group } \\
\text { (200 screws) }\end{array}$ & P value \\
\hline Placement accuracy & 4 & 2 & 0.490 \\
Medial pedicle breach & $24^{*}$ & 11 & $0.003 \dagger$ \\
Lateral pedicle breach & $2^{*}$ & 0 & 0.197 \\
Endplate tresis & $3^{*}$ & 0 & 0.087 \\
Foraminal tresis & 0 & 0 & 1.000 \\
Anterior vertebral body breach & $30 / 160(18.75 \%)$ & $13 / 200(6.50 \%)$ & $0.000 \dagger$ \\
Total & 1 & & \\
Complications & 2 & 0 & 0.444 \\
CSF leak & 1 & 1 & 0.844 \\
Durotomy & 2 & 0 & 0.444 \\
Nerve root injury & 1 & 0 & 0.195 \\
Surgical site infection & 0 & 0 & 1.000 \\
Pseudarthrosis & $7 / 40$ & $1 / 50$ & 1.000 \\
Hardware malfunction & $90.00 \%(36 / 40)$ & $88.00 \%(44 / 50)$ & $0.028 \dagger$ \\
Total & & & \\
Fusion rate & & &
\end{tabular}


CSF, cerebrospinal fluid.

* There is one lateral pedicle breach screw penetrating the upper endplate and two lateral pedicle breach screws penetrating the foramen.

† $P<0.05$, statistically significant.

\section{Figures}

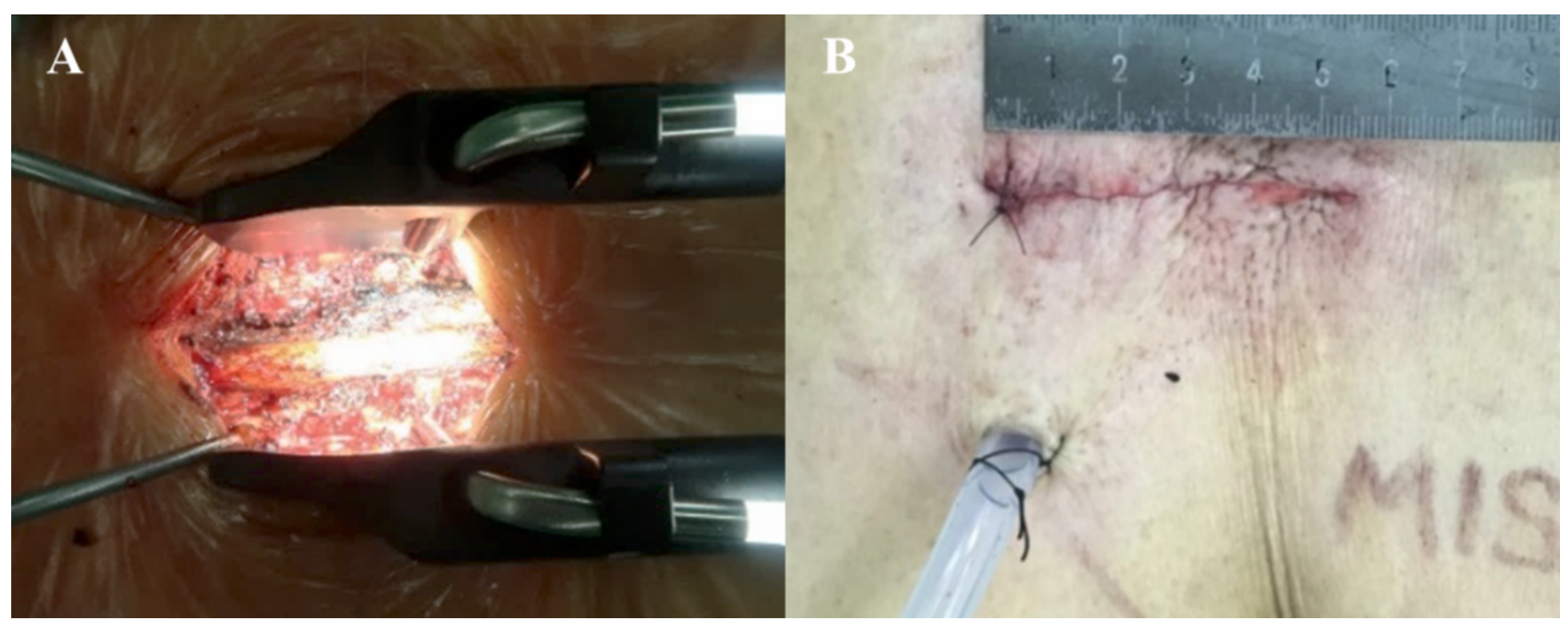

\section{Figure 1}

The images of intraoperative exposure and incision. $A$, the intraoperative exposure image shows the limited space of operation; $B$, the incision and drain tube. 


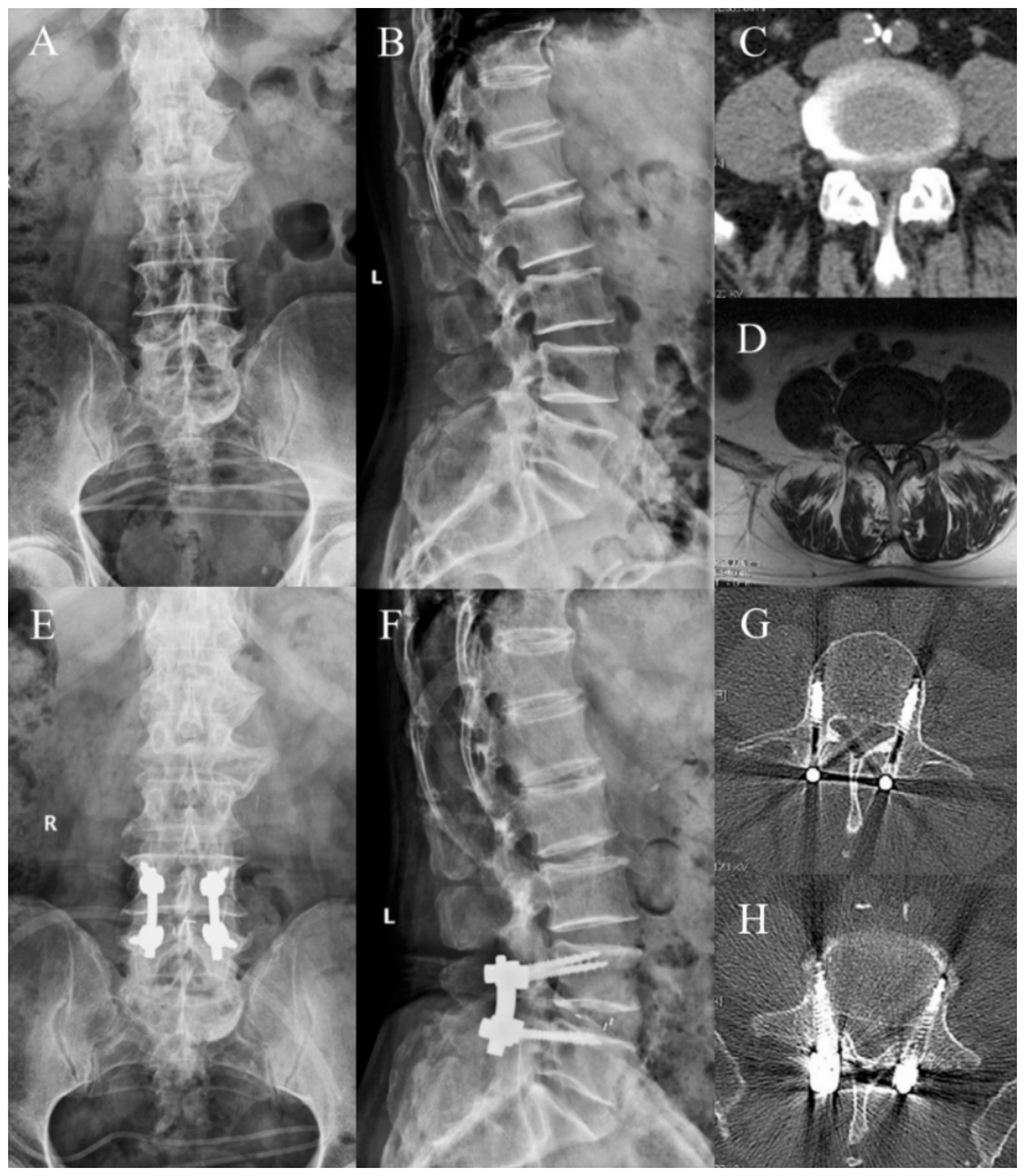

\section{Figure 2}

Radiological examination of one patient with lumbar spinal stenosis at $L 4 / 5$ segment with failure conservative treatment. A, Anteroposterior view of pre-operation lumbar spine X-Ray; B, Lateral view of pre-operation lumbar spine X-Ray; C, L4/5-disc axial image of pre-operation CT scan; D, L4/5-disc axial image of pre-operation MRI scan; E, Anteroposterior view of 3 mos. post-operation lumbar spine X-Ray; F, 
Lateral view of 3 mos. post-operation lumbar spine X-Ray; G, Cortical screws position in L4 vertebrae; $H$, Cortical screws position in L5 vertebrae.

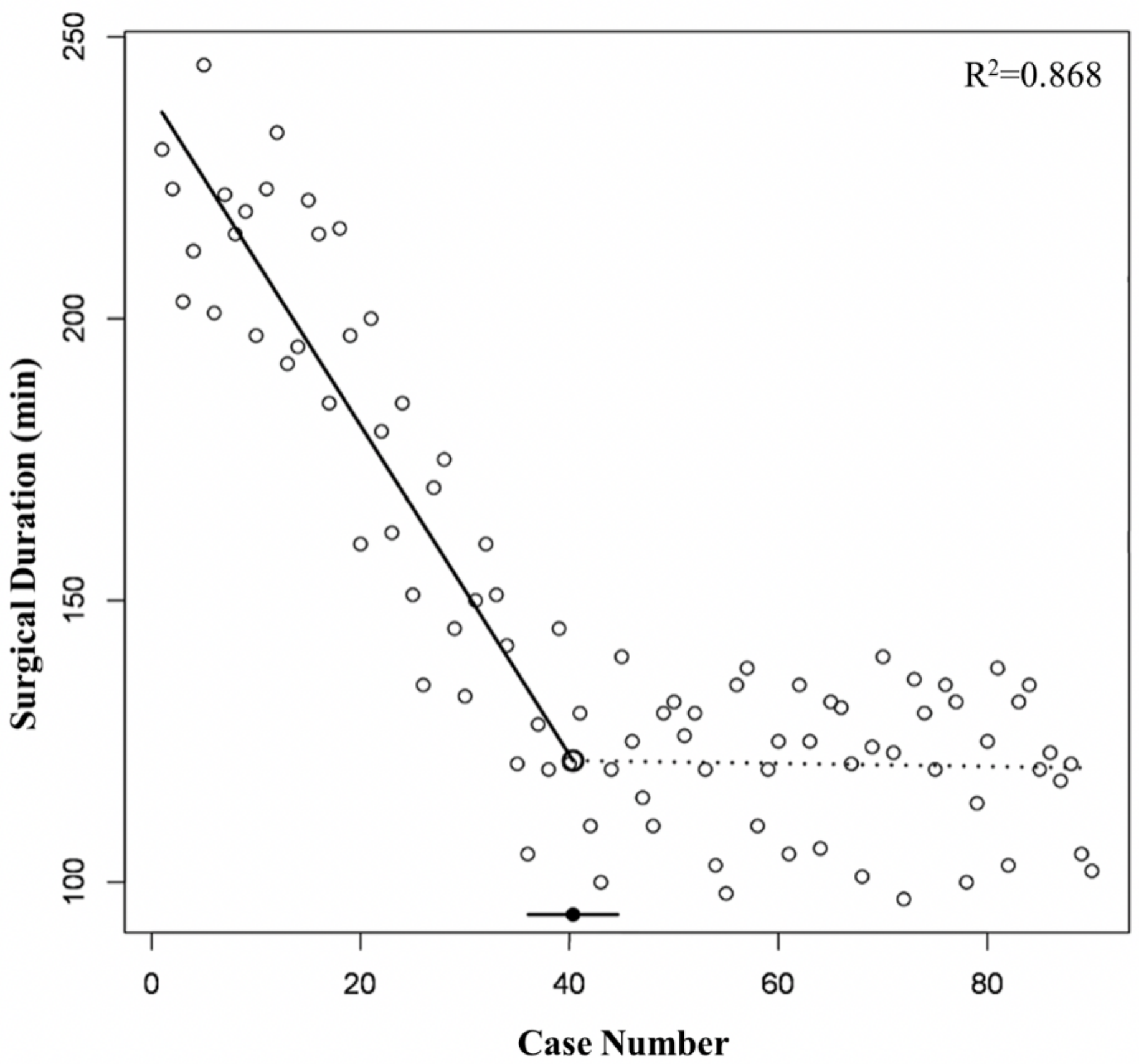

Figure 3

Learning curve based on surgical time plotted against case number. Learning curve based on surgical time plotted against case number, the bar above the $x$-axis represents the breakpoint estimate (40) and its $95 \%$ confidence limits (38-42 patients) 


\section{Frequency distribution of cortical screw size}

200

180 176

160

140

120

100

80

60

40

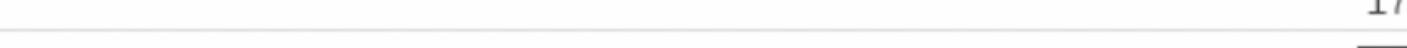

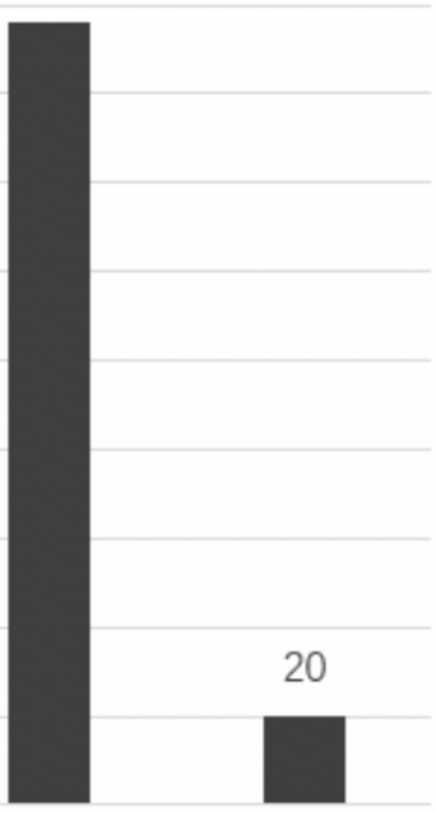

0

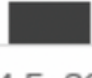

$4.5 * 30$

$4.5 \star 35$

$5.0 * 30$

$5.0 * 35$

$5.5 * 30$

$5.5 * 35$

$5.5 * 40$

- Cortical Screw Size width*length (mm)

\section{Figure 4}

Frequency distribution of cortical screw size. Cortical screws with width of $5.5 \mathrm{~mm}$ and length of $35 \mathrm{~mm}$ $\left(5.5^{\star} 35 \mathrm{~mm}\right)$ were most frequently used. 


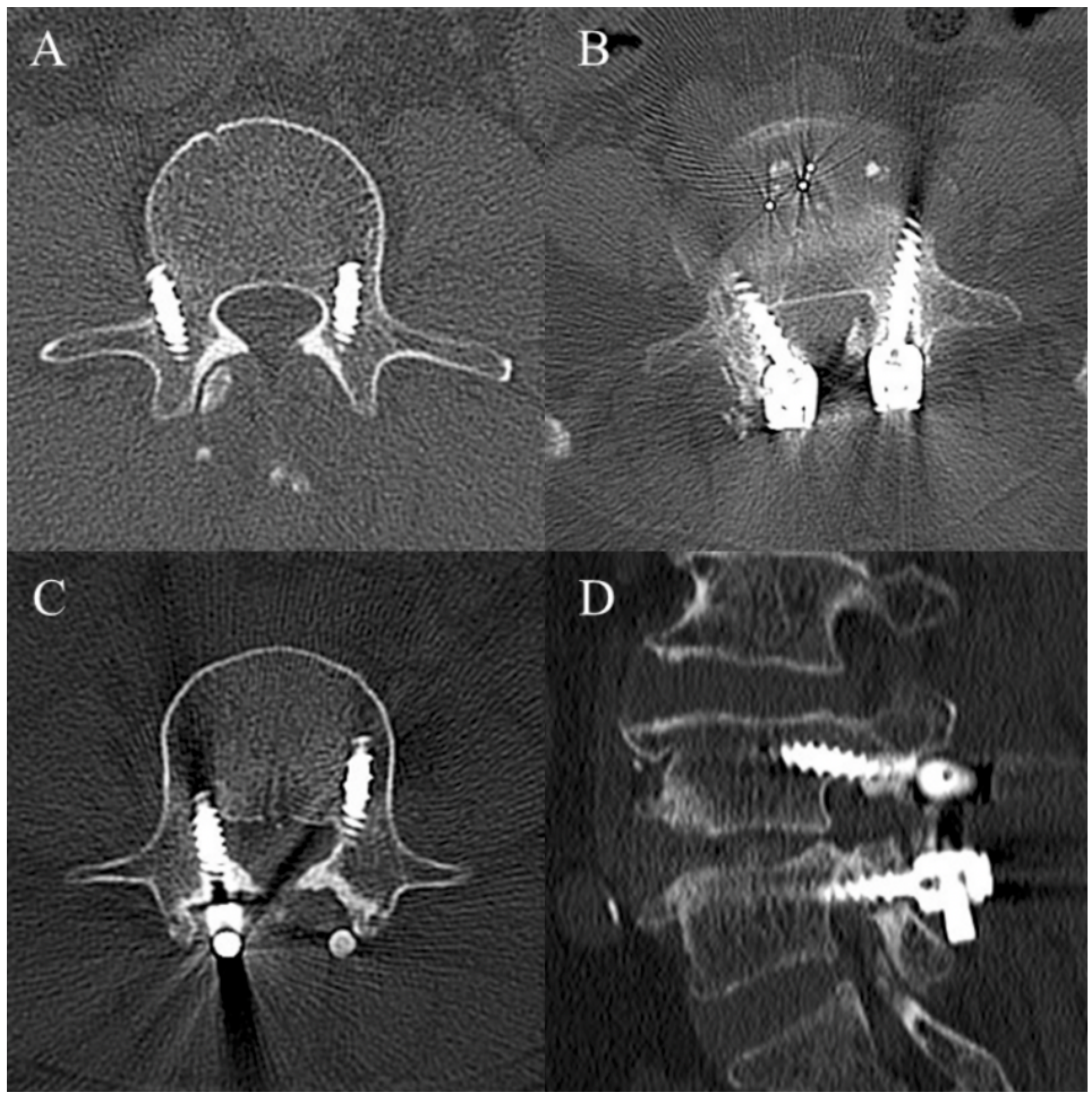

\section{Figure 5}

Lumbar spine computer tomography (CT) images of the misplacement screws. A, a laterally placed screw (the left screw); B, a medial pedicle breach screw leading to CSF leak (the left screw); C, a medially placed screw with no complication (the left screw); D, a foraminal tresis screw (the inferior screw). 